\title{
Literature review of non-operative management of patients with blunt splenic injury: impact of splenic artery embolization
}

\author{
Krystyn Sosada, Maciej Wiewióra, Jerzy Piecuch \\ Department of General and Bariatric Surgery and Emergency Medicine School of Medicine with the Division of Dentistry in Zabrze, \\ Medical University of Silesia in Katowice, Poland
}

Videosurgery Miniinv (e-pub, ahead of print) DOI: 10.5114/wiitm.2014.44251

\begin{abstract}
Splenic injuries constitute the most common injuries accompanying blunt abdominal traumas. Non-operative treatment is currently the standard for treating hemodynamically stable patients with blunt splenic injuries. The introduction of splenic angiography has increased the possibility of non-operative treatment for patients who, in the past, would have qualified for surgery. This cohort includes mainly patients with severe splenic injuries and with active bleeding. The results have indicated that applying splenic angioembolization reduces the frequency of non-operative treatment failure, especially in severe splenic injuries; however, it is still necessary to perform prospective, randomized clinical investigations.
\end{abstract}

Key words: splenic injuries, angiography, angioembolization.

\section{Introduction}

Abdominal organ injuries are found in $20 \%$ to $30 \%$ of patients with multi-organ injuries [1, 2]. Splenic injuries constitute the most common injuries accompanying blunt abdominal traumas [3, 4]. Splenic damage represents approximately $3 \%$ of injuries found in patients after blunt injuries [5]. Blunt splenic injury has various therapeutic options depending on the patient's hemodynamic condition and the accompanying injuries of other organs. Surgery remains the gold standard for treating patients with splenic injuries with hemodynamic instability and it has constituted $31-35 \%[6,7]$ or even up to $50 \%$ of cases [8]. Over the last few years, a distinct trend in spleen saving has been observed and increasing numbers of patients with these injuries have been treated non-operatively [9], including patients with abdominal multi-organ injuries [10]. Presently, non-operative procedures in blunt splenic traumas are also being recommended in hemody- namically stable patients [11]; similarly, they have already been recommended for children [12, 13]. Non-operative treatment, combined with splenic artery angioembolization, is among the options for the treatment of hemodynamically stable patients, regardless of splenic injury severity $[5,14]$.

\section{Non-operative treatment}

This multi-centre study enrolled more than 200000 traumatic patients, of whom 6308 were patients with blunt splenic injuries, observed according to the changing trends in spleen injury treatment in adults [5]. It was found that the frequency of immediate operations decreased from 52\% in 1993 to $39 \%$ in 1997 . Simultaneously, the frequency of unsuccessful non-operative treatments decreased from $13.5 \%$ to $10.08 \%$, proportional to the severity of spleen injury evaluated according to the American Association for the Surgery of Trauma (AAST) grading system, grade IV and V, respectively, occur-

\section{Address for correspondence}

Maciej Wiewióra MD, PhD, Department of General and Bariatric Surgery and Emergency Medicine, Medical University of Silesia,

10 Sklodowskiej-Curie St, 41-800 Zabrze, Poland, phone: +48 3237323 81, e-mail: m-wiewiora@tlen.pl 
ring in $33.3 \%$ and $75 \%$. It was also found that two thirds of patients in whom conservative treatment was not effective were operated on within $24 \mathrm{~h}$ after hospital admission, while only $13.8 \%$ and $6.9 \%$ required changes in treatment on the second and third days, respectively. The degree of splenic injury and the size of intraperitoneal hematoma were indices for non-operative treatment success. Conservative treatment was effective in $80 \%$ of patients with a small hematoma, defined as perisplenic blood, in more than $50 \%$ of patients with a medium-sized hematoma, defined as the presence of blood around the pericolonic groove on one side or on both sides, and nearly one third $(27.4 \%)$ of patients with large hematomas, defined as the presence of blood in the pelvis minor.

The ReCONECT study included patients with spleen injuries of grades IV and $\mathrm{V}$ according to the AAST scale, finding that $42 \%$ of these patients required immediate operations, while $58 \%$ were treated conservatively at first [15]. Thirty-eight percent of patients from the second group required operations within the next few days, of whom more than two thirds required surgery within the first $24 \mathrm{~h}$ after admission. Operative treatment was necessary in 249 of 388 patients (64\%), including $60 \%$ with grade IV and $83.5 \%$ with grade $V$ spleen injuries. Multifactor analysis showed two independent conservative treatment failure factors: grade $\mathrm{V}$ according to the AAST grading system of spleen injury and cerebral trauma. Another large analysis included 23532 patients with blunt splenic injuries, of whom $89 \%$ had initially non-operative treatment, and the success rate of these procedures was $78 \%$. The frequency of non-operative failure was proportional to spleen injury severity, according to the AAST scale and according to the Injury Severity Score [16]. Another study found that the success rate of non-operative treatment of hemodynamically stable patients with spleen injuries was as high as $90 \%$ [17]. Many studies have attempted to establish prognostic factors for non-operative treatment failure in patients with blunt spleen injuries in stable hemodynamic conditions. The failure predictors of non-operative spleen injury treatment have included age older than 50 years old, severe spleen injury estimated according to the AAST scale, the presence of a large hematoma in the peritoneal cavity and injury severity estimated using the Injury Severity Score (ISS) [15, 17-21]. Olthof et al. undertook a systematic review of stud- ies to identify prognostic factors for non-operative treatment failure of blunt spleen injuries [22]. Age $\geq 40$ years old, severity of injury according to ISS score $\geq 25$ and grade of spleen injury according to AAST scale $\geq 3$ were counted among the strong predictors of conservative treatment failure. Following another analysis, the non-operative treatment failure rate was estimated to be $4-52 \%$, with a mean of $12 \%$ [23]. This analysis consisted of 25 studies: 4 prospective and 16 retrospective. Sixteen studies of high quality were graded on the basis of the Newcastle-Ottawa Scale (NOS). Severe spleen injuries, estimated using the AAST scale with a cut-off point greater than 3 or 4 , the presence of a large intraperitoneal hematoma and age older than 55 years were strongly correlated with conservative treatment failure. The analysis also included 5 studies in which spleen artery angioembolization was applied. It was found that embolization reduced the risk of conservative treatment failure (OR $0.26,95 \% \mathrm{Cl}: 0.13-0.53$; $p<0.002$ ). The authors of both analyses emphasized the lack of randomized studies in this area. Historically, splenectomy was the treatment of choice for patients with traumatic splenic injury. Over the last decade, non-operative management has become the preferred treatment for hemodynamically stable patients with blunt splenic injury. Selective non-operative management of abdominal trauma is safe and has been shown to reduce the rate of unnecessary laparotomy. The role of laparoscopy in blunt trauma has yet to be clearly defined. Laparoscopic splenectomy has become the gold standard in some hematological diseases [24-27]. However, a series of cases of blunt abdominal trauma in which laparoscopy was used as a therapeutic tool has been reported [28].

\section{Angiography and embolization}

In 1981, Sclafani presented a series of 4 patients with splenic injuries, in whom angiography and embolization of the splenic artery were applied [29]. To date, many studies have confirmed the effectiveness of spleen artery angioembolization in hemodynamically stable patients with spleen injuries, through decreases in indices of conservative treatment failure and in the necessity of surgery, especially in cases of severe injuries [30-34]. Sabe et al. presented a retrospective analysis of a period of 16 years, including 815 patients treated due to blunt spleen injuries [35]. The patients were divided into 3 groups 
with regard to the frequency of angioembolization application. In the first group, angioembolization was not applied as a routine procedure (1991-1998); in the second group, it was introduced and applied discretionarily (1998-2001); and in the third group, angioembolization was used as a routine procedure (2002-2007) in patients with a high risk of conservative treatment failure. As criteria for initial splenic artery embolization (SAE) treatment, the presence of extravasation or a false aneurysm on $\mathrm{CT}$ and grade III spleen injury with a large hematoma or grade IV injury according to the AAST scale were acknowledged. A total of 647 (79\%) patients qualified for non-operative treatment. The frequency of successful conservative treatment in each group over the years increased proportionally with the frequency of SAE application. Simultaneously, a significant decrease in mortality from $5.8 \%$ in group I to $1.2 \%$ in groups II and III was found. Among 109 patients in groups II and III, who received SAE as their initial treatment, only 5 procedures (4.6\%) ended in failure, while among 47 patients, who received SAE in later stages, technical failure occurred only in 1 case. Two patients required splenectomy and 3 required splenorrhaphy. The results presented by the National Trauma Registry of the American College of Surgeons regarded the influence of embolization on treatment results in patients with splenic injuries in the period 2000-2010 [36]. In a group of 1039 patients, 539 (63\%) were managed non-operatively, including 104 patients who had either a proximal embolization of the splenic artery or both proximal embolization and selective distal splenic artery embolization. Angioembolization was applied in hemodynamically stable patients in whom active bleeding and splenic injury of grade IV or V were found and/or a decreasing level of hemoglobin was observed. The total index of conservative treatment failure was similar in both groups at $4 \%$. The frequency of non-operative treatment failure was compared between the two groups, with SAE and without SAE, depending on the severity of spleen injury according to AAST. No significant differences were found in the frequency of non-operative treatment in patients with grade I-III spleen injuries. However, in grade IV and V spleen injury, the index of non-operative treatment failure was significantly higher in patients who were not treated with angioembolization, compared to those who received angioembolization: $23 \%$ vs. $3 \%(p=0.04)$ in grade IV; and $63 \%$ vs. $9 \%(p=0.03)$ in grade V. Angioembo- lization of the splenic artery reduced the rate of conservative treatment failure from $33 \%$ to $7 \%$ ( $p=$ 0.009). Logistic regression analysis showed that grade IV and V spleen injuries and contrast blush on CT were independent factors in non-operative treatment failure. Hemodynamically stable patients with active bleeding and injuries of grade V/VI had, respectively, 22 and 5 times greater probability of treatment failure if AE was not applied. The results of other studies have shown that the presence of contrast blush on CT was correlated with contrast extravasation on angiography and was correlated with a definitely higher risk of conservative treatment failure [36-38]. Bhullar et al. found a strong correlation between the presence of contrast blush on $C T$ and active bleeding found on angiography [39]. Fifty-six percent of the patients with contrast blush found on CT had spleen injury of grades IV and $\mathrm{V}$ and $44 \%$ of grade I-III, according to AAST. Angiography was performed in $93 \%$ of these patients and contrast extravasation on angiography confirmed active bleeding in $98 \%$. All these patients received splenic artery angioembolization and the applied treatment failure rate was $3 \%$ in the entire group, although it was $6 \%$ in patients with grade IV and V spleen injuries. Among the $7 \%$ of patients with contrast blush who did not undergo angiography, the non-operative treatment failure rates in the entire group were $71 \%$ and $100 \%$, respectively, in patients with grade IV and V spleen injuries. The results of this study confirmed the statement that CT contrast blush indicated the necessity of applying angioembolization in patients with blunt spleen injuries who qualified for non-operative treatment. The authors also suggested that hemodynamically stable patients with grade IV and V spleen injuries should undergo angiography, even when no contrast blush has been found. Thirty-nine percent of patients underwent angiography, although there was no CT contrast blush, which confirmed active bleeding in $85 \%$, and embolization appeared to be effective in all the cases. Injury of splenic vessels in the form of false aneurysms and posttraumatic arteriovenous fistulas have also been acknowledged to be factors related to a higher risk of non-operative treatment failure and these factors indicate the need for angioembolization and surgery [40, 41]. Requarth et al. presented a meta-analysis in which they compared the effectiveness of non-operative treatment of patients with blunt spleen injuries, regarding whether the 
treatment included additional spleen artery embolization [42]. The analysis also involved 24 studies in the period from 1994 to 2009, including only 1 non-randomized cohort study (evidence level II). No randomized studies were found on this subject. The analysis included 10157 patients treated due to splenic injury, of whom $68 \%$ were treated non-operatively. Embolization of the splenic artery was applied in only 4 studies, including a total of 393 patients. The study's analysis confirmed the clearly inverse dependence between the success of conservative treatment and the grade of spleen injury, which ranged from $4.3 \%(95 \% \mathrm{Cl}: 2.5-7.4)$ to $83.1 \%(95 \% \mathrm{Cl}$ : $54.2-96.7)$ for spleen injury grade I to $V$ according to AAST. Splenic artery embolization significantly improved the results of non-operative treatment of patients with spleen injuries. The treatment failure rate in the group of patients in whom splenic artery embolization was applied, in comparison to those without embolization, was lower: $17.3 \%(95 \% \mathrm{Cl}$ : 7.8-34.1) vs. $43.7 \%$ (95\% Cl: $25.5-63.8 ; p=0.035)$ for grade IV; and $25 \%(95 \% \mathrm{Cl}: 8.7-53.8)$ vs. $83.1 \%$ (95\% Cl: $45.2-96.7 ; p=0.016)$ for grade $\vee$ spleen injuries. In the group of patients in whom the splenic artery was embolized, the failure rate was $15.7 \%$ (95\% Cl: 10.4-23.2). The authors found that routine splenic artery embolization after blunt splenic injuries of grades IV and $V$ could improve the results of non-operative treatment; however, this finding must be confirmed in further studies. Embolization can refer to the main trunk of the splenic artery (proximal embolization), terminal branches of the splenic artery (distal embolization) or segmental arteries (selective distal splenic artery embolization). Thus far, there has been no consensus regarding the type of embolization that provides the best results and that minimizes the number of complications. Schnüriger et al. presented a systematic review of studies, in which they compared the frequency of complications after proximal and distal embolization of the splenic vessels [43]. Their primary issues for analysis were bleeding, infarction and infection requiring splenectomy or splenorrhaphy, and they were defined as serious complications. If the complications did not require splenectomy, they were considered minor complications. The study included 11 studies published in 1995-2008 and involving 479 embolized patients. No randomized or cohort studies were found that compared the results of proximal versus distal embolization. The total frequency of angioem- bolization failure was $10.2 \%$, which was within the range of $0.0-33.3 \%$ for each study. No significant difference was found in the frequency of major complications between proximal and distal embolization. The frequency of bleeding, splenic infarction and infection after proximal embolization versus distal embolization was, respectively, $4.7 \%$ vs. $6.3 \%, 0.0 \%$ vs. $1.6 \%$, and $1.9 \%$ vs. $0.0 \%$. A trend toward a decreasing frequence of splenic infarction after proximal embolization versus distal embolization was found and this trend was, respectively, $0.0-0.5 \%$ vs. $1.6-3.8 \%$. Only 1 patient with splenic infarction required surgery after proximal embolization with the use of a coil, which was dislocated distally. However, in the group of minor complications, significantly more frequent splenic infarction was found after distal embolization versus proximal embolization: $14.3 \%$ vs. $0.0 \%$. In the authors' opinion, there was no explicit proof of an advantage for any of the methods, so prospective and randomized studies are still required. A comparable number of serious complications were observed that required splenectomy after proximal versus distal embolization, while minor complications, which did not require splenectomy, occurred more often after distal embolization. Delphi's study, based on the opinions of 30 international experts, attempted to reach a consensus on treating patients after blunt splenic injuries [44]. The experts agreed that observation or angioembolization could be applied in hemodynamically stable patients in cases with no bleeding or with minor intraperitoneal bleeding, defined as perisplenic blood with accompanying intraparenchymal contrast extravasation or without extravasation, regardless of the presence of an arterio-venous (AV) fistula or pseudoaneurysm. In cases of patients with severe splenic injuries and light bleeding with the presence of an AV fistula/false aneurysm, $79 \%$ of experts indicated angioembolization in cases of intraparenchymal contrast extravasation, while $71 \%$ indicated angioembolization if the extravasation occurred intraperitoneally. In cases of major intraparenchymal bleeding, defined as the presence of blood around the spleen, along the pericolonic groove and/or in the pelvis minor and intraperitoneal contrast extravasation, half of the experts would attempt angioembolization. However, if the contrast extravasation was into the parenchyma, $67 \%$ to $71 \%$ of experts would choose angioembolization. The recommended time to begin splenic artery embolization in cases 
of intraparenchymal bleeding was $60 \mathrm{~min}$ (79\% of experts), while it was 30-60 min in cases of intraperitoneal bleeding ( $92 \%$ of experts).

\section{Conclusions}

Non-operative treatment is currently the standard for treating hemodynamically stable patients with blunt splenic injuries. The introduction of splenic angiography has increased the possibility of non-operative treatment for patients who, in the past, would have qualified for surgery. This cohort includes mainly patients with severe splenic injuries and with active bleeding. The results indicated that applying splenic angioembolization reduces the frequency of non-operative treatment failure, especially in severe splenic injuries; however, it is still necessary to perform prospective, randomized clinical investigations.

\section{References}

1. Deunk J, Brink M, Dekker HM, et al. Predictors for the selection of patients for abdominal CT after blunt trauma: a proposal for a diagnostic algorithm. Ann Surg 2010; 251: 512-20.

2. Søreide K. Epidemiology of major trauma. Br J Surg 2009; 96 : 697-8.

3. Velmahos GC, Toutouzas KG, Radin R, et al. Nonoperative treatment of blunt injury to solid abdominal organs: a prospective study. Arch Surg 2003; 138: 844-51.

4. Raza M, Abbas Y, Devi V, et al. Non operative management of abdominal trauma - a 10 years review. World J Emerg Surg 2013; 8: 14

5. Peitzman AB, Heil B, Rivera L, et al. Blunt splenic injury in adults: multi-institutional Study of the Eastern Association for the Surgery of Trauma. J Trauma 2000; 49: 177-87.

6. Meguid AA, Bair HA, Howells GA, et al. Prospective evaluation of criteria for the nonoperative management of blunt splenic trauma. Am Surg 2003; 69: 238-42.

7. Myers JG, Dent DL, Stewart RM, et al. Blunt splenic injuries: dedicated trauma surgeons can achieve a high rate of nonoperative success in patients of all ages. J Trauma 2000; 48: 801-5.

8. Heuer M, Taeger G, Kaiser GM, et al. No further incidence of sepsis after splenectomy for severe trauma: a multi-institutional experience of the trauma registry of the DGU with 1,630 patients. Eur J Med Res 2010; 15: 258-65.

9. Notash AY, Amoli HA, Nikandish A, et al. Non-operative management in blunt splenic trauma. Emerg Med J 2008; 25: 210-2.

10. Yanar H, Ertekin C, Taviloglu K, et al. Nonoperative treatment of multiple intra-abdominal solid organ injury after blunt abdominal trauma. J Trauma 2008; 64: 943-8.

11. Stassen NA, Bhullar I, Cheng JD, et al. Selective nonoperative managementof blunt splenic injury: an Eastern Association for the Surgery of Trauma practice management guideline. J Trauma Acute Care Surg 2012; 73: S294-300.
12. Jacobs IA, Kelly K, Valenziano C, et al. Nonoperative management of blunt splenic and hepatic trauma in the pediatric population: significant differences between adult and pediatric surgeons? Am Surg 2001; 67: 149-54.

13. Bird JJ, Patel NY, Mathiason MA, et al. Management of pediatric blunt splenic injury at a rural trauma center. J Trauma Acute Care Surg 2012; 73: 919-22.

14. Marmery H, Shanmuganathan K, Alexander MT, Mirvis SE. Optimization of selection for nonoperative management of blunt splenic injury: comparison of MDCT grading systems. AJR Am J Roentgenol 2007; 189: 1421-7.

15. Velmahos GC, Zacharias N, Emhoff TA, et al. Management of the most severely injured spleen: a multicenter study of the Research Consortium of New England Centers for Trauma (ReCONECT). Arch Surg 2010; 145: 456-60.

16. Smith J, Armen S, Cook CH, et al. Blunt splenic injuries: have we watched long enough? J Trauma 2008; 64: 656-63.

17. Renzulli P, Gross T, Schnüriger B, et al. Management of blunt injuries to the spleen. Br J Surg 2010; 97: 1696-703.

18. Meguid AA, Bair HA, Howells GA, et al. Prospective evaluation of criteria for the nonoperative management of blunt splenic trauma. Am Surg 2003; 69: 238-42.

19. McIntyre LK, Schiff M, Jurkovich GJ. Failure of nonoperative management of splenic injuries: causes and consequences. Arch Surg 2005; 140: 563-8.

20. Jeremitsky E, Kao A, Carlton C, et al. Does splenic embolization and grade of splenic injury impact nonoperative management in patients sustaining blunt splenic trauma? Am Surg 2011; 77 : 215-20.

21. Fu CY, Wu SC, Chen RJ, et al. Evaluation of need for operative intervention in blunt splenic injury: intraperitoneal contrast extravasation has an increased probability of requiring operative intervention. World J Surg 2010; 34: 2745-51.

22. Olthof DC, Joosse P, van der Vlies $\mathrm{CH}$, et al. Prognostic factors for failure of nonoperative management in adults with blunt splenic injury: a systematic review. J Trauma Acute Care Surg 2013; 74: 546-57.

23. Bhangu A, Nepogodiev D, Lal N, et al. Meta-analysis of predictive factors and outcomes for failure of non-operative management of blunt splenic trauma. Injury 2012; 43: 1337-46.

24. Migaczewski M, Zub-Pokrowiecka A, Budzyński P, et al. Prevention of early infective complications after laparoscopic splenectomy with the Garamycin sponge. Videosurgery Miniinv 2012; 7: 105-10.

25. Pędziwiatr M, Matłok M, Major P, et al. Laparoscopic surgery of the spleen through single umbilical incision. Videosurgery Miniinv 2013; 8: 8-12.

26. Su CH, Yin TC, Huang CJ, et al. Laparoscopic splenectomy for splenomegaly using a homemade retrieval BAG. Videosurgery Miniinv 2013; 8: 327-33.

27. Krasowski G, Budzynski A, Miodoński M, et al. Laparoscopic splenectomy complicated by pancreatic cyst in the course of Hodgkin's disease: case report. Videosurgery Miniinv 2013; 8: 352-6.

28. Nasr WI, Collins CL, Kelly JJ. Feasibility of laparoscopic splenectomy in stable blunt trauma: a case series. J Trauma 2004; 57: 887-9. 
29. Sclafani SJ. The role of angiographic hemostasis in salvage of the injured spleen. Radiology 1981; 141: 645-50.

30. Haan JM, Biffl W, Knudson MM, et al. Splenic embolization revisited: a multicenter review. J Trauma 2004; 56: 542-7.

31. Wu SC, Chow KC, Lee KH, et al. Early selective angioembolization improves success of nonoperative management of blunt splenic injury. Am Surg 2007; 73: 897-902.

32. Bhullar IS, Frykberg ER, Siragusa D, et al. Age does not affect outcomes of nonoperative management of blunt splenic trauma. J Am Coll Surg 2012; 214: 958-64.

33. Wei B, Hemmila MR, Arbabi S, et al. Angioembolization reduces operative intervention for blunt splenic injury. J Trauma 2008; 64: $1472-7$.

34. Ekeh AP, Khalaf S, Ilyas S, et al. Complications arising from splenic artery embolization: a review of an 11-year experience. Am J Surg 2013; 205: 250-4.

35. Sabe AA, Claridge JA, Rosenblum DI, et al. The effects of splenic artery embolization on nonoperative management of blunt splenic injury: a 16-year experience. J Trauma 2009; 67: 565-72.

36. Bhullar IS, Frykberg ER, Siragusa D, et al. Selective angiographic embolization of blunt splenic traumatic injuries in adults decreases failure rate of nonoperative management. Trauma Acute Care Surg 2012; 72: 1127-34.

37. Davis KA, Fabian TC, Croce MA, et al. Improved success in nonoperative management of blunt splenic injuries: embolization of splenic artery pseudoaneurysms. J Trauma 1998; 44: 1008-13.

38. Haan J, Scott J, Boyd-Kranis RL, et al. Admission angiography for blunt splenic injury: advantages and pitfalls. I Trauma 2001; 51: 1161-5.

39. Bhullar IS, Frykberg ER, Tepas JJ 3rd, et al. At first blush: absence of computed tomography contrast extravasation in Grade IV or $\checkmark$ adult blunt splenic trauma should not preclude angioembolization. J Trauma Acute Care Surg 2013; 74: 105-11.

40. Haan JM, Bochicchio GV, Kramer N, et al. Nonoperative management of blunt splenic injury: a 5-year experience. J Trauma 2005; 58: 492-8.

41. van der Vlies $\mathrm{CH}$, van Delden OM, Punt BJ, et al. Literature review of the role of ultrasound, computed tomography, and transcatheter arterial embolization for the treatment of traumatic splenic injuries. Cardiovasc Intervent Radiol 2010; 33: 1079-87.

42. Requarth JA, D’Agostino RB Jr, Miller PR. Nonoperative management of adult blunt splenic injury with and without splenic artery embolotherapy: a meta-analysis. J Trauma 2011; 71: 898903.

43. Schnüriger B, Inaba K, Konstantinidis A, et al. Outcomes of proximal versus distal splenic artery embolization after trauma: a systematic review and meta-analysis. J Trauma 2011; 70: 252-60.

44. Olthof DC, van der Vlies CH, Joosse P, et al. Consensus strategies for the nonoperative management of patients with blunt splenic injury: a Delphi study. J Trauma Acute Care Surg 2013; 74: 1567-74.

Received: 21.11.2013, accepted: 23.06.2014. 